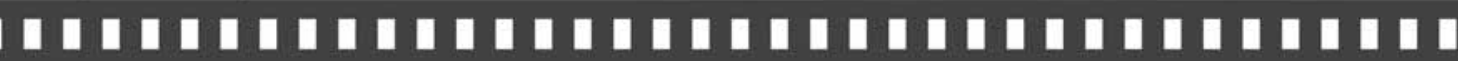 Uma análise discursiva sobre parcialidade, pluralidade de vozes e princípio do contraditório em uma agência estadual de notícias

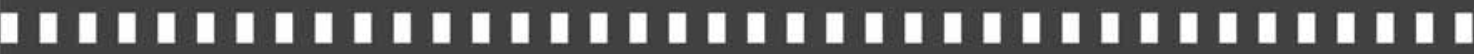

\author{
Angela Maria Rubel Fanini \\ Maurini Souza \\ Disonei dos Santos Pereira
}

Artigo recebido em: 25/02/2014

Artigo aprovado em:18/06/2015 


\title{
Uma análise discursiva sobre parcialidade, pluralidade de vozes e princípio do contraditório em uma agência estadual de notícias
}

\author{
Adiscursive analysis on partiality, plural speeches and principle \\ of contradictory in a state news agency
}

\author{
Angela Maria Rubel Fanini* \\ Maurini Souza ** \\ Disonei dos Santos Pereira***
}

\begin{abstract}
Resumo: Esta pesquisa investigou como ocorre a construção de imagem na comunicação externa da Agência Estadual de Notícia (AEN) do governo do Estado do Paraná, com uma apreciação por meio da análise do discurso de Orlandi (1999), seguindo conceitos de Foucault (1971) e a crítica à postura da imprensa brasileira efetuada por Arbex Jr. (2003). O corpus selecionado constituiu-se de três reportagens da AEN publicadas no segundo semestre de 2011, e a metodologia, de natureza qualitativa e de estudo de caso, deu a conhecer o modo como os critérios jornalísticos são adaptados para influenciar o enquadramento no conceito de comunicação pública, o engajamento da população, a garantia do debate público.
\end{abstract}

Palavras-chave: Imagem. Comunicação pública. Análise do discurso. Imprensa.

\begin{abstract}
This paper investigated how image is built within the external communication of the State News Agency (AEN) of the government of Paraná state through a discursive analysis grounded on Orlandi (1999), following concepts from Foucault (1971), and the critical view towards Brazilian journalism pointed by Arbex Jr. (2003).. The selected corpus comprised three news releases from AEN in the second semester of 2011, and the methodology, qualitative in nature and of case study type, allowed for the perception of the ways journalistic criteria are held to influence the agency role in the concept of public communication, the involvement of the population, the assurance of public debate.
\end{abstract}

Keywords: Image. Public communication. Discourse analysis. Press.

* Doutora em Literatura Brasileira pela UFSC. Docente no Programa de Pós-Graduação em Tecnologia e dos Cursos de Comunicação e Letras da UTFPR. Email: rubel@utfpr.edu.br

** Doutora em Estudos Linguísticos pela UFPR. Docente dos Cursos de Comunicação e Letras da UTFPR. Email: maurinis@yahoo.com.br

*** Especialista em Comunicação Institucional e Empresarial pela UTFPR e em Gestão e Produção de Rádio e Televisão pela Universidade Tuiuti do Paraná, UTP. Jornalista do Jornal de Raízes Diário, RD, Brasil. 


\section{Introdução}

As informações produzidas pela Agência Estadual de Notícia (AEN) são de extrema importância para a população do Estado do Paraná, pois grande parte dos jornais, principalmente do interior do estado, que não possui uma equipe de produção na capital, utiliza as informações da AEN em suas páginas. As notícias são transmitidas à população dentro de um contexto de agência de notícias, que deveria ser um canal independente entre o estado (e não governo) e os veículos de comunicação. A agência é diferente de uma assessoria de imprensa, que divulga releases para a imprensa como sugestão de pauta, embora as informações das agências de notícias também possam ser usadas como sugestão de pauta.

Esta pesquisa levou em conta o conceito de comunicação pública, que difere de promoção pública dos gestores que ocupam os cargos no governo. A análise do discurso francesa, sobretudo alguns conceitos extraídos da obra de Foucault (1971) e da pesquisadora brasileira em AD, Orlandi (1999), formam a base do estudo para identificar o conteúdo ideológico contido nas notícias da AEN.

Esta pesquisa é de natureza aplicada de abordagem qualitativa. Para este estudo de caso, foram utilizadas três reportagens da AEN, por serem exemplares, publicadas no segundo semestre de 2011. As reportagens analisadas foram divulgadas nos dias 8 de agosto, 11 de outubro e 5 de dezembro (em anexo). As notícias foram analisadas de acordo com a proposta de Orlandi (1999), seguindo conceitos de Foucault (1971) e a crítica à postura da imprensa brasileira efetuada por Arbex Jr. (2003). Seguindo o percurso elaborado por Orlandi (1999), primeiro foi feita uma análise da superfície do texto e, em seguida, os elementos que determinam as relações do texto com as formações ideológicas são descritos sob a ótica da passagem do objeto discursivo pelo processo discursivo. 


\section{AAgência Estadual de Notícias}

Como o objeto de estudo deste trabalho é a AEN, é importante relatar o histórico da instituição até aqui, a fim de situar sua importância na comunicação do estado. A ideia de se criar uma agência de notícia estadual surge no mandato do então governador do Estado, Álvaro Dias (1986/ 1991), mas só é consolidada na gestão de seu sucessor, Roberto Requião (1991/1994), mais precisamente em 1991 (RIBAS, 2010).

Segundo Felipe Freitas Ribas (2010), a AEN só fortaleceu sua representatividade no cenário comunicacional do Paraná com a consolidação tecnológica. O autor destaca que, em 2004, primeiro ano em que a Agência esteve integralmente online, foram divulgadas 4.099 notícias. Esse número foi ampliado nos períodos seguintes, sendo que, em 2008, foram publicadas 9.391 matérias e, de 2004 a 2009, foram 46.568 reportagens, uma média de aproximadamente 21 notícias por dia.

AAEN foi criada com a necessidade de uniformização do serviço de Comunicação Social do Governo e também como a Assessoria desejava chegar de forma mais rápida e incisiva nas redações dos jornais do Estado. Inicialmente este novo setor é nomeado como de Departamento de Divulgação. Em 1987 se torna Secretaria de Estado da Comunicação e, só em 2000, é que se configura a AEN, vinculada à Secretaria de Comunicação.

Segundo levantamento feito por Ribas (2010), a distribuição do material produzido pelos jornalistas era impresso com o auxílio de mimeógrafos, em 1978, e levado de carro até as redações dos jornais da capital. Já para o interior, a distribuição era feita através dos serviços dos Correios: “Em 1983, foi implantado telégrafo na redação. A partir daí os Correios deixaram de participar do processo de distribuição, dando lugar para a utilização do telex. Mas na capital, as notícias continuavam a ser levadas por carros” (IDEM. p. 29).

A informatização da redação da Secretaria de Estado de Comunicação só ocorre em 1994, no Governo de Jaime Lerner, depois 
das privatizações de estatais como Telepar e Banestado. O envio de matérias passou a ser feito pelos telefones com fax. Os computadores só chegaram em 1995, mas os serviços de internet ainda não permitiam transferência de muito dados, como imagens, por exemplo. Apenas em 1997 é que as matérias começaram a ir para as redações dos jornais da capital por e-mails.

Com a nova eleição de Roberto Requião, em 2003, e já com a Secretaria de Comunicação informatizada e bem estruturada é que ocorre a implantação do endereço eletrônico www.aen.pr.gov.br/ e cria-se o site da ANP, o qual fora desenvolvido pela Companhia de Informática do Paraná (Celepar).

Ribas (2010) destaca que com este suporte puderam ser divulgadas pela Agência tanto notícias, quanto fotos, vídeos e áudios, além de serviços, como links de empresas ou outras páginas ligadas ao Governo e ouvidorias. Um benefício relevante deste suporte foi a criação de um banco de dados em que se pode buscar o que foi divulgado desde o ano de 2003. Seis anos depois, o site teve seu layout renovado, cujo conteúdo os interessados pelas notícias oficiais do Estado podem acessar atualmente. (IDEM, p. 30).

Na gestão do governador Beto Richa, a AEN vinculou-se à Secretaria de Estado de Comunicação Social. Passam a ser divulgadas informações em texto, áudio e foto. De janeiro a dezembro de 2011, primeiro ano do governo Beto Richa, a Agência Estadual publicou 5.667 notícias.

\section{A comunicação pública}

Por se tratar de uma agência que visa divulgar informações do setor público, é importante analisar estudos realizados sobre a comunicação pública. Elizabeth Pazita Brandão (2009) classifica a comunicação pública em cinco áreas diferentes do conhecimento e atividade profissional: 1- 
Conhecimento e técnica de área de comunicação organizacional; 2 comunicação científica; 3 - comunicação do Estado e/ou governamental; 4 - comunicação política; e 5 - comunicação da sociedade civil organizada. É o conceito de comunicação do Estado e/ou governamental que vai permear este estudo. Segundo a autora, essa é uma dimensão da comunicação pública que é de responsabilidade do Estado e do governo de estabelecer um fluxo informativo e comunicativo com seus cidadãos. Essa comunicação deveria trabalhar com a informação voltada para a cidadania, ouvindo a população em suas demandas e prestando contas das políticas públicas implantadas. A pesquisadora afirma que:

[...] comunicação governamental pode ser entendida como comunicação pública, na medida em que ela é instrumento de construção da agenda pública e direciona seu trabalho para a prestação de contas, o estímulo para o engajamento da população nas políticas adotadas, o reconhecimento das ações promovidas nos campos políticos, econômico e social, em suma, provoca o debate público. (BRANDÃO, 2009, p. 5).

A autora ressalta que a comunicação pública está longe de ser um instrumento de promoção política dos governos, mas é uma forma legítima de um governo prestar contas e levar ao conhecimento da opinião pública projetos, ações, atividades e políticas que realiza e que são de interesse público. Porém, o que se verifica em nível nacional é o uso dos aparatos comunicacionais públicos como meio de promoção daqueles que estão no poder. Segundo Bucci (2009), as instituições públicas que operam a comunicação social no Brasil, sejam elas empresas estatais, fundações ou departamentos ligados diretamente ao Governo, atuam como pequenas máquinas de propaganda a serviço das autoridades do poder executivo. "Em lugar de informar, dedicamse a tentar formar a opinião pública segundo os moldes que interessam ao governo da temporada” (BUCCI, 2009, p. 192). O autor traz como exemplo bem sucedido de comunicação pública a postura adotada 
pela Radiobrás, empresa que concentra emissoras de rádio, televisão e agência de notícias na internet (hoje Empresa Brasil de Comunicação, EBC) a partir do governo Luiz Inácio Lula da Silva, em 2003. A empresa foi direcionada para realizar uma comunicação a serviço da cidadania, não mais para a promoção da boa imagem de governos, o que, segundo os modelos originados nos tempos da ditadura militar, muitas vezes resultava em notícias distorcidas e na sonegação de informações. Com esse novo modelo, a comunicação foi se tornando “apartidária”. Segundo o autor, o reconhecimento pelo trabalho é o crescimento da audiência, na utilização cada vez mais ampla de seus conteúdos, que são gratuitos para os órgãos de imprensa.

Bucci (2009) ressalta que o resultado foi obtido com a implementação de valores como: respeito ao caráter público da atividade, ao buscar a excelência e ao exercer a transparência, interna e externa; respeito à cidadania, ao assumir o compromisso permanente com a universalização do direito à informação, por meio do canal direto com o público; respeito às diferenças, por meio do diálogo; respeito às pessoas, ao promover a felicidade no trabalho, a criatividade e a inovação. Tendo o respeito como base, a ética se concretiza na renovação cotidiana de credibilidade da Radiobrás junto à sociedade brasileira e aos funcionários da empresa. Segundo o autor, não é função da Radiobrás tutelar ou direcionar a formação da opinião pública, mas dar informações necessárias para que os cidadãos formem a própria opinião. Para os governos que não querem transparência na divulgação das informações, Bucci (2009) traz trecho do documento que serviu para fundamentar a prática editorial da Radiobrás:

[...] qualquer governo voltado para a renovação e fortalecimento da democracia é beneficiário de uma comunicação jornalística pautada pela objetividade. Para um governo democrático, é muito bom que uma empresa pública de comunicação ofereça ao público um relato jornalístico objetivo, pois a objetividade gera um aumento da credibilidade da instituição, o que reverte em mais credibilidade do Estado e do próprio Governo. (BUCCI, 2009, p. 198). 
Essa recomendação é importante para a AEN, pois seu conteúdo não seria somente a versão do governo sobre determinado tema, mas diferentes versões do fato, já que não teria interferência política na divulgação das informações oficiais do Estado.

\section{A imparcialidade do discurso jornalístico}

O termo “agência de notícias” remete a uma empresa jornalística especializada em difundir informações e notícias diretamente das fontes para os veículos de comunicação ${ }^{1}$. As agências não fornecem notícias diretamente ao público, mas sim para jornais, revistas, rádios, TVs, websites, enfim, para a mídia em geral. Por isso, as agências de notícias, sejam elas públicas ou privadas, devem seguir critérios jornalísticos e transmitir credibilidade.

Flor e Bonfim (2005), citados por Ribas (2010), fazem a seguinte distinção entre as diversas propostas de agências de notícias:

a) Particulares, que surgem por iniciativas não-oficiais e são administradas como órgão ou empresa privada. b) Cooperativas, partem do consórcio de vários jornais que contribuem para mantêlas. c) Estatais, surgem criadas pelos governos. d) Gerais, tratam de todo e qualquer assunto. e) Especializadas, a difundir determinada classe de serviços. f) Atualidades Fotográficas, divulgam apenas ilustrações. g) De Artigos, contratam matérias de nomes consagrados do jornalismo nacional e internacional. h) Nacionais, produzem apenas para empresas jornalísticas do país que atuam. j) Internacionais, divulgam informações de e para todo o mundo. (FLOR; BONFIM, 2005, p.5)

AAEN é o órgão de divulgação do governo do Estado do Paraná e se enquadra na proposta de agência estatal. Seu conteúdo é reproduzido

Disponível em http://pt.wikipedia.org/wiki/Ag\%C3\%AAncia_de_not\%C3\%ADcias. Acesso em 13 de maio de 2012. 
por sites, rádios e jornais. Em média, suas notícias são usadas na íntegra, ou como fonte, nos maiores veículos de comunicação do Estado, o que pode ser comprovado pelo clipping produzido pelo próprio órgão (RIBAS, 2010).

Devido à propagação do conteúdo na imprensa de todo o Estado, é importante entender o discurso que é projetado pelas informações da AEN na sua constituição social e política. Os discursos que permeiam a sociedade são controlados e perpassados por formas de poder e de repressão. Foucault, ao destacar a prática discursiva, enfoca essa problemática, enfatizando: "suponho que em toda sociedade a produção do discurso é ao mesmo tempo controlada, selecionada, organizada e redistribuída por certo número de procedimentos que tem por função conjurar seus poderes, dominar seu conhecimento aleatório [...]” (FOUCAULT, 1996, p.8-9).

O papel das agências de notícias estatais seria divulgar informações ao público dos governos que elas representam, sendo selecionadas de acordo com a importância para a população. Em caso de algum assunto controverso, o governo teria o espaço para se defender. Como uma das atitudes do poder, que é evidenciado neste trabalho, é controlar o discurso, com a finalidade de manutenção do status quo, as agências acabam fazendo o papel de uma assessoria de comunicação dos governos.

Para Foucault (1996), a política é um dos temas que exerce poder sobre a sociedade e o discurso:

[...] longe de ser um elemento transparente ou neutro no qual a sexualidade se desarma e a política se pacifica, é como se o discurso fosse um dos lugares onde estas regiões exercem, de maneira privilegiada, algumas dos seus mais temíveis poderes. O discurso, aparentemente, pode até nem ser nada de por aí além, mas, no entanto, os interditos que o atingem, revelam, cedo, de imediato, o seu vínculo ao desejo e o poder. (FOUCAULT, 1996, p. 2 -3).

O autor demonstra as condições para que os indivíduos possam formular seus discursos. A primeira forma discutida é o ritual que determina 
a qualificação que os sujeitos que falam devem ter, define o comportamento, as circunstâncias, como também a eficácia desse discurso e o efeito desse discurso sobre aqueles a quem é dirigido. A segunda forma são as sociedades de discurso "cuja função é conservar ou produzir discursos, mas para fazê-los circular em um espaço fechado, distribuí-los somente segundo regras estritas” (Idem p.39). A doutrina, por sua vez (que também determina o modo como o indivíduo criará seu discurso), procura difundir seu discurso para o maior número de pessoas, contudo, “a única condição requerida é o reconhecimento das mesmas verdades e a aceitação de certa regra mais ou menos flexível de conformidade com os discursos validados” (p.42). E, por fim, o sistema de educação, que “é uma maneira política de manter ou de modificar a apropriação dos discursos, com os saberes e os poderes que eles trazem consigo”. (p.44).

No caso, o discurso produzido na AEN está endossado pela palavra do próprio governador ou de representante do alto escalão do governo, como os secretários de Estado. Esse discurso, geralmente, remete a uma comparação entre o atual governo e o anterior, ressaltando as partes positivas da atual gestão.

Os interesses políticos do governo podem ser um entrave na livre divulgação de informações, principalmente aquelas que são negativas para o grupo que está no poder. José Arbex Jr. (2003) ressalta que o “efeito mercado” contamina os diversos campos da produção cultural e, dentre eles, o jornalismo, que é regido por um conjunto de efeitos que estão ligados, em sua forma e eficácia, à sua estrutura própria. A autonomia de certos jornais e jornalistas está submetida a forças externas, do mercado de leitores e do mercado de anunciantes. A receita proveniente do mercado publicitário e da ajuda do Estado difunde o grau de autonomia. Já no caso de uma Agência Estatal, que funciona como uma assessoria de imprensa do governo, o controle do conteúdo pode ser ainda maior porque a comunicação é um dos artifícios para o governo se promover e continuar no poder: “A notícia, como produto final, é uma síntese desse conjunto de relações, que ganharam ainda mais complexidade a partir de meados dos anos 80, com a formação das redes planetárias de comunicação (como é 
o caso da CNN) e dos grandes conglomerados multinacionais” (ARBEX Jr. 2003, p. 98 - 99).

Os governos são fontes riquíssimas de informações. Boa parte do noticiário é produzido com base em fontes oficiais, isto é, muitas informações são oriundas dos governos. E os detentores dessa informação têm o poder de controlá-las e divulgar somente o que lhes for de interesse, principalmente nas agências de notícias governamentais. Não só divulgam, mas interpretam as informações de acordo com sua conveniência. E isso não é exclusividade das agências de notícias estatais, mas da mídia em geral. Arbex Jr (2003) diz que “a mídia cria diariamente sua própria narrativa e a apresenta aos telespectadores - ou aos leitores - como essa narrativa fosse a própria história do mundo” (Idem. p. 103). O autor ressalta que os fatos são transformados em notícia, descritos como eventos independentes, completos em si mesmo, levando o espectador a acreditar que aquilo que vê é o mundo em estado natural.

O real é formado de acordo com o que é passado pela mídia. Arbex Jr (2003) diz que a ideia de que a notícia como retrato do fato tal como ele realmente aconteceu nasceu junto com a própria atividade jornalística; por outro lado, querer que as agências públicas apresentem uma informação pautada na objetividade jornalística seria um equívoco, já que o autor defende que a objetividade é mito na imprensa. Essa percepção teria surgido com a ideia da arte romântica do século XIX, quando a verdade da imagem dependia do grau de fidelidade à paisagem observada, ou do realismo que pressupunha que o trabalho artístico deveria ser regido pela experiência direta da realidade.

Tendo em vista as colocações de Foucault (1996) e Arbex Jr (2003), o rígido controle da informação por parte dos governos e a filtragem do que pode ser publicado acaba indo além das agências de notícias e chegando até o jornalismo diário. Com isso os discursos feitos pelos governos, com os seus interesses, chegam até o alvo, que é a população que os elege. Através de liberação de recursos em forma de cotas publicitárias, os governos repassam o seu discurso para o público por meio da imprensa. A dependência de verbas publicitárias dos governos 
por parte dos veículos de comunicação torna-se uma “força externa”, que contamina a objetividade do jornalismo. Temendo a perda das receitas publicitárias governamentais, os jornais acabam se autocensurando, e não publicam ou amenizam informações negativas dos governos, contrariando a postura apontada por Bucci (2009) de que, apesar do caráter mercadológico da notícia, a função social da informação de interesse público não se reduz à condição de mercadoria. (p. 197).

Para se alcançar a função social da informação nas reportagens, é necessário pluralidade de fontes. No caso das agências públicas de notícias, o uso de fontes do próprio governo que confirmam uma informação ou a interpretam, vai contra o que é defendido pelas normas do jornalismo. A controvérsia é inerente ao fato, e críticas ao governo são encontradas na imprensa independente, mas não se observam na agência pública do Paraná porque a AEN se submete aos interesses de quem está no poder.

\section{O discurso}

Para compreender o que os receptores das informações produzidas pelas agências governamentais de notícia recebem, pode-se recorrer à análise do discurso. Segundo Eni Orlandi (1999), a análise do discurso conhece a linguagem como mediação necessária entre o homem e a realidade natural e social. "Essa mediação, que é o discurso, torna possível tanto a permanência e a continuidade quanto o deslocamento e a transformação do homem e da realidade em que vive. O trabalho do simbólico do discurso está na base da produção da existência humana” (Idem, p. 15). Ou seja, o discurso constitui toda ação humana, mas nem tudo é perceptível.

A autora ressalta que a análise do discurso não trabalha com a língua enquanto um sistema abstrato, mas com a língua no mundo, com maneiras de significar, com homens falando, considerando a produção de sentidos enquanto parte de suas vidas, seja enquanto sujeitos, seja enquanto 
membros de uma determinada forma de sociedade. (p.16). Ela sugere que o discurso é o lugar em que se pode observar a relação entre língua e ideologia, compreendendo-se como a língua produz sentidos para o sujeito.

Vale lembrar que a análise do discurso não procura um sentido verdadeiro por meio de uma chave de interpretação, mas trabalha com a construção de um dispositivo teórico que defende a não existência de uma só verdade oculta no texto. Há gestos diversos de interpretação que o constituem e que o analista, com seu dispositivo, deve ser capaz de compreender.

No caso da AEN, é comum as notícias tratarem de temas relacionados ao governo, mas omitirem algumas informações que são negativas ou polêmicas; por esse motivo, este estudo procurou analisar assuntos que foram polêmicos ou causaram algum desgaste para o governo. Orlandi (1999) ressalta que é necessário considerar o que é dito em um discurso e o que é dito em outro, o que é dito de um modo e o que é dito de outro modo, procurando escutar o não-dito naquilo que é dito, como a presença de uma ausência necessária (p. 34). Esse deve ser um dos dispositivos de interpretação. Para a autora, o sentido não existe em si, mas é determinado pelas posições ideológicas colocadas em jogo no processo sócio-histórico em que as palavras são produzidas. $\mathrm{O}$ fato de não haver sentido sem interpretação atesta a presença da ideologia (p. 45). Para Orlandi (1999), um dos primeiros pontos da base de análise é a constituição do corpus. A delimitação não segue critérios empíricos, mas teóricos. Quanto à analise da linguagem, a análise do discurso se interessa por diferentes naturezas: imagem, som, letras. A autora divide em três etapas as fases da análise do discurso. Na primeira, o analista, em contato com o texto, procura ver nele sua discursividade e incidindo um primeiro lance de análise. Nesse momento da análise, é fundamental o trabalho com paráfrase, sinonímia, relação do dizer e do não dizer. Na segunda etapa, a partir do objeto discursivo, o analista vai incluir uma análise que procura relacionar as formações discursivas distintas, que pode ser delineado no jogo de sentidos observados pela análise do processo de significação com a formação ideológica que rege essas relações. A terceira 
etapa é a análise da passagem do processo discursivo para a formação ideológica. $\mathrm{O}$ analista deve se ater ao não-dito e a forma de se trabalhar o não-dito na análise do discurso é contextualizar o silêncio. Este pode ser pensado como a respiração da significação, lugar de recuo necessário para que se possa significar, para que o sentido faça sentido (p. 83).

\section{Análise das notícias}

Antes de iniciar a análise das notícias da AEN, é importante compreender o contexto político do atual governo do Paraná. Para Orlandi (1999), o discurso não tem como função constituir a representação de uma realidade, no entanto, ele funciona de modo a assegurar a permanência de uma certa representação (IDEM. p. 73). O governador Beto Richa (PSDB) foi eleito em 2010, depois de deixar a Prefeitura de Curitiba, onde exercia o segundo mandato. O governador sucedeu Roberto Requião (PMDB), que governou o Estado por três mandatos, sendo os dois últimos consecutivos. Beto Richa chegou ao governo sem o apoio de Requião e é a primeira vez que o PSDB governa o Estado.

Para esta pesquisa, foram analisadas três notícias, veiculadas no período de julho a dezembro de 2011. O segundo semestre foi escolhido porque, nos primeiros seis meses, o governo estava ainda na fase de adequações. Para a seleção, foram levados em conta assuntos que trouxeram algum tipo de polêmica ou desgaste que podem dar uma amostra de como é transmitido ao público a imagem do atual governo por meio das notícias da AEN. Orlandi (1999) ressalta que não se toma o texto como ponto de partida absoluta, nem de chegada, mas como uma peça de linguagem de um processo discursivo bem mais abrangente e é assim que deve ser considerado. Ele é um exemplar do discurso (p. 72).

A primeira matéria analisada refere-se à retirada da pauta da Assembleia Legislativa do Paraná (Alep), por parte do executivo, do projeto de lei que criava a Agência Reguladora do Estado do Paraná 
(Agepar). A segunda é sobre o projeto que instituiu a Parceria Público Privada (PPP) no governo do Estado e a outra sobre a o projeto de lei que autoriza o governo a repassar para Organizações Sociais (OS) a execução de serviços que até então estavam sob a responsabilidade do Estado.

\section{Matéria: Governo retira da Assembleia projeto da Agência}

Reguladora, veiculada no dia 08 de agosto de 2011.

Segundo Orlandi (1999, p.67) é importante analisar o modo de construção, a estruturação, o modo de circulação e os diferentes gestos de leituras que constituem os sentidos dos textos submetidos à análise. A matéria inicia afirmando que, por decisão do governador Beto Richa, o governo do Estado solicitou a retirada da pauta da Assembleia Legislativa e a devolução do projeto que criava a Agepar. A frase "por decisão do governador" passa uma imagem de que a retirada do projeto foi feita voluntariamente e por vontade soberana do governador, sem que existisse pressão por parte da oposição, imprensa e até mesmo por membros do próprio governo.

Pelo projeto do governo, a Agepar iria fiscalizar todas as concessionárias de serviços públicos que atuam no Estado, receberia como Taxa de Regulação 0,5\% da receita operacional bruta de cada empresa. Porém a proposta encontrou forte resistência da bancada de oposição e de alguns deputados do PMDB, partido da base aliada, que acusavam o governo de, com a medida, tentar privatizar a Copel e a Sanepar.

Orlandi (1999) lembra que uma das tarefas do analista é tornar visível o que não foi dito em relação ao que foi dito. A matéria em momento algum cita a polêmica da privatização, que chegou a ser chamada pela oposição de agência privatizadora. A única menção que submete ao tema é uma fala do líder do governo na Assembleia, Ademar Traiano, que diz que a retirada do projeto teve a "intenção de revisar e melhorar o texto para que não pairem dúvidas sobre as intenções da proposição”. O leitor da AEN que não esteja a par do assunto, terá dificuldade para entender do que se trata. A fala do líder afirma que o governo quer fortalecer as 
empresas públicas, mas não usa a palavra privatização. No caso, há uma contradição entre o discurso do governo e da oposição. Fortalecer as empresas públicas foi a forma do governo dizer que não irá privatizar as estatais do Paraná. O texto poderia dizer que o governo não pretende privatizar as estatais como Copel e Sanepar, porém o termo privatização soa como uma força ideológica negativa para o governo do estado devido às privatizações do governo Fernando Henrique Cardoso (1995 a 2002), que pertencia ao mesmo partido do governador Beto Richa. $\mathrm{O}$ assunto foi estratégico na campanha do PT contra o PSDB nas últimas três eleições presidenciais.

Privatização é um objeto simbólico que produz sentido, como ressalta Orlandi. A autora destaca que entre as inúmeras possibilidades de formulação, os sujeitos dizem x e y, significando, produzindo-se em processos de significação que aparecem como se estivessem referidos a sentidos que ali estão, enquanto produtos da relação evidente de palavras e coisas (p. 67). O PSDB sempre relutou em abolir a imagem de governo privatista, e no caso do Paraná, o governo Beto Richa não quer deixar espaço para que o tema seja explorado em 2014, quando o partido vai tentar a reeleição.

A matéria encerra afirmando que o projeto passará por uma revisão de texto e será reencaminhado para votação na Assembleia. Com isso, não ficou claro o real motivo da retirada do projeto e a polêmica das privatizações ficou em oculto, apontando para a postura de Orlandi (1999) de que o silêncio é o não-dito e também faz parte do discurso, significando. No discurso, o que há de real é a descontinuidade, a dispersão, a incompletude, a falta, o equívoco, a contradição, constitutivas tanto do sujeito como do sentido. Por outro lado, em nível das representações, temos a unidade, a completude, a coerência, o claro e distinto, a não contradição, na instância do imaginário. É por essa articulação necessária, e sempre presente entre o real e o imaginário que o discurso funciona (Idem, p. 74).

Essa afirmação remete ao fato de que o assunto estava na imprensa há vários dias, sempre pautado pela polêmica das privatizações. O governo 
só se pronunciava sobre o assunto diretamente com os veículos de comunicação através da assessoria de imprensa. A matéria só saiu na AEN quando o governo decidiu retirar o projeto da Assembleia.

\section{Matéria: Emendas para saúde, segurança, educação e social} terão prioridade, diz Richa, veiculada no dia 11 de outubro de 2011.

A matéria trata de uma reunião com cerca de 40 deputados estaduais em que o governador Beto Richa discute com os parlamentares o orçamento para 2012 e, em segundo plano, apresenta as linhas básicas do projeto que instituía as Parcerias Público-Privadas (PPPs) no Estado.

Enquanto as PPPs eram o tema principal nos veículos de comunicação, a AEN tratou o assunto como tema secundário. O título da matéria tem pouco a ver com o foco principal da notícia, que é a discussão do orçamento para 2012. As PPPs só vão aparecer no sétimo parágrafo da matéria e com ampla defesa do assunto. A justificativa do governo é que a medida permitiria ao poder público driblar a falta de condições técnicas e financeiras enfrentadas em inúmeras situações e garantir, com o apoio da iniciativa privada, o pleno atendimento das necessidades dos paranaenses. O tema, porém, dividiu a opinião de especialistas. Enquanto alguns afirmavam que, se bem formatada, essa era uma maneira interessante de prestar serviços de qualidade à população, havia quem defendia que as PPPs serviam, na verdade, para que entes privados obtivessem lucro com o respaldo e a proteção do poder público. No entanto, a matéria defende apenas a tese do governo. A começar pelo título, que não faz nenhuma menção às PPPs, apenas diz que saúde, educação, segurança e social é prioridade no governo. O tripé saúde, educação e segurança sempre foi defendido por especialistas como pilares do desenvolvimento e os temas são promessas em épocas de eleições. Novamente há um termo ideológico que o governo evita. $\mathrm{O}$ termo $\mathrm{PPP}$ remete à concessão pública para o setor privado, a privatizações. No entanto, nessa matéria o termo privatização é citado uma vez (única). Ao defender o projeto, o secretário de planejamento, Cássio Taniguchi, afirma que com as PPPs, “ao fim do prazo [das concessões à iniciativa privada], que geralmente é 
longo, aquele bem é devolvido ao setor público, o que torna um processo diferente de privatização”. Desde o início do governo Beto Richa, a palavra privatização aparece apenas cinco vezes na AEN. Além da citação nessa matéria, em outras duas, o termo se refere à entrega de bens públicos para a iniciativa privada na atual gestão. As outras duas se referem à privatização do Banestado e da Rede Ferroviária Federal ocorridas em governos anteriores.

Orlandi (1999) afirma que todo discurso se estabelece na relação com um discurso anterior e aponta para outro. Ela diz que não há discurso fechado em si mesmo, mas um processo discursivo do qual se podem recortar e analisar estados diferentes (p. 62). Assim, a defesa do projeto que institui as PPPs, mesmo defendendo que não há venda dos bens do Estado para a iniciativa privada, leva a subentender que existe privatização. Ainda no primeiro parágrafo da matéria, há uma citação do governador Beto Richa que diz que “o diálogo é a marca forte do governo e queremos manter abertos os canais com todos os representantes da população paranaense no legislativo”. Esse discurso remete ao governo anterior, que recebia crítica por não dialogar com a sociedade. Com isso, Beto Richa cria um elemento de comparação entre as duas gestões. Vale ressaltar que os deputados que compareceram ao encontro fazem parte da base de apoio do governo e que a situação é maioria absoluta na Assembleia. Além do título, no segundo parágrafo, é enfatizado que as áreas de saúde, segurança pública, educação e desenvolvimento social são prioridade no plano de governo e terão privilégio para liberação de recursos na execução do orçamento de 2012. Endossam as palavras do governador, o secretário-chefe da Casa Civil, Durval Amaral, o presidente da Assembleia Legislativa, deputado Valdir Rossoni e o líder do governo no legislativo, deputado Ademar Traiano, contribuindo para fortalecer o discurso do executivo. Em torno do discurso executivo, surgem outros discursos que o abonam, comentam e reforçam.

Na matéria, há um tópico sobre as PPPs e a informação de que os parlamentares assistiram a uma palestra com um especialista da consultoria internacional KPMG. AAEN afirma ainda que a empresa é parceira do 
Movimento Brasil Competitivo (MBC), entidade com a qual o Governo do Paraná assinou um protocolo de intenções para implantar o programa Modernizando a Gestão Pública.

O consultor da empresa, Charles Schramm, é um dos que defende o projeto para os deputados. "É uma demonstração séria de quem deseja resolver os problemas da sociedade”, diz uma citação na matéria. A frase inserida na matéria coloca o governo como uma espécie de super-herói que vai sanar os problemas da população paranaense. Como a empresa é parceira do governo do Estado, logo existe interesse da KPMG pelo projeto. Orlandi (1999) afirma que o discurso funciona como mecanismo para assegurar a permanência de uma certa representação. Isso fica claro com as declarações de quem tem interesse na continuidade do atual governo no poder.

Defendem ainda o projeto, o secretário do Planejamento, Cássio Taniguchi e o secretário da Infraestrutura e Logística, José Richa Filho, irmão do governador; os argumentos contrários não são apresentados, como o "não-dito", que significa. A pluralidade de fontes e a dialética não estão presentes na matéria da AEN. Ao final, a matéria traz a informação de que o governo do Estado criou uma explicação com perguntas e respostas sobre as PPPs. Não seria para receber sugestões e promover o diálogo, como o governo prega, mas para “tirar dúvidas”, isto é, reforçar ainda mais o único ponto de vista oferecido à população.

\section{Matéria: Gestores da área da saúde apoiam projeto de} Organizações Sociais, publicada no dia 05 de dezembro de 2011.

A matéria aborda o projeto de lei que foi encaminhado à Assembleia Legislativa pelo Executivo que autoriza o governo a repassar para Organizações Sociais (OS) a execução de serviços sob a responsabilidade do Estado. Pela proposta, o governo poderia entregar às OSs a gestão de todos os serviços públicos, com exceção do ensino regular - ensinos fundamental, médio e superior - e da segurança pública. O projeto foi criticado pela oposição, que classificou como um "retrocesso, a terceirização da função do Estado com outras roupas”. Novamente foi 
usado o termo privatização para designar a transferências das responsabilidades do Estado à iniciativa privada, mais precisamente para as Organizações Não Governamentais (ONGs). No dia da votação do projeto, ocorrida no dia 5 de dezembro, manifestantes invadiram o plenário da Assembleia Legislativa em protesto. Reivindicava-se que o projeto fosse discutido com a sociedade por meio de audiência pública. A matéria publicada na AEN, no mesmo dia da votação, trata de uma reunião com gestores de hospitais particulares e filantrópicos que poderiam ser beneficiados com a proposta. O texto traz depoimentos do diretor do Hospital Pequeno Príncipe e do superintendente do Hospital Erasto Gaertner. Ambos defendem o projeto. Amatéria não menciona nenhuma polêmica sobre a proposta e vai contra um dos princípios básicos do jornalismo, que seria a multiplicidade das fontes. Não existe dialética na matéria da AEN. Na época, as Organizações Não Governamentais (ONGs) eram alvos de denúncias de desvios e descaminhos do dinheiro público nos convênios com o governo federal. O diretor do Hospital Pequeno Príncipe culpou os escândalos envolvendo as ONGs pela resistência ao projeto das OSs no Paraná.

Lembrando que, na $\mathrm{AD}$, é necessário considerar o que é dito em um discurso e o que é dito em outro, procurando escutar a presença de uma ausência necessária (ORLANDI, 1999. p. 34). Enquanto que na impressa paranaense em geral o assunto era pautado pela polêmica de que, com a terceirização, os serviços de saúde poderiam piorar, a matéria da AEN silencia sobre esse ponto e somente pontua os pontos positivos do projeto e o interesse do governo. Como a aprovação do projeto estava garantida na Assembleia pelo fato de o governo ser maioria, o discurso da matéria está focado na defesa do projeto para a sociedade, com o objetivo de evitar desgastes para o governo. Na prática, houve uma contradição no que o governo prega e o que é feito. O governo não aceitou fazer audiências públicas, o que contradiz o discurso do próprio governador, de que "o diálogo é a marca forte do governo", citado por Beto Richa na primeira matéria analisada. 


\section{Considerações finais}

Esta pesquisa teve por objetivo analisar as matérias da AEN para verificar o nível de tendenciosidade das informações. A análise confirmou que as matérias da agência não seguem critérios jornalísticos regidos pela dialética e pelo princípio do contraditório, como deveria ocorrer em uma agência de notícias. AAEN se comporta como uma assessoria de imprensa do governo do Estado. Além de selecionar as obras positivas do governo, as matérias evitam casos polêmicos e, quando tratam, apontam apenas os interesses do governo.

Orlandi (1999) ressalta que um discurso sempre remete a outro discurso. No caso do governo do Estado, o discurso está voltado para uma comparação com o governo anterior, que era chefiado por Roberto Requião. A frase do presidente da Assembleia Legislativa, Valdir Rossoni (PSDB), que diz que "esse debate facilita a tramitação e adianta a votação e aprovação do orçamento, que antes era feita apenas no último dia da legislatura", referindo-se à discussão do orçamento para 2012, é uma crítica ao governo passado. O confronto com o já dito visa fortalecer o governo atual e não promover o debate e revelar o contraditório.

A análise permite concluir que a comunicação do governo do Estado está longe de se enquadrar no conceito de comunicação pública. Brandão (2009) afirma que a comunicação governamental pode ser entendida como comunicação pública, na medida em que ela é instrumento de construção da agenda pública e direciona seu trabalho para a prestação de contas, o estímulo para o engajamento da população nas políticas adotadas, o reconhecimento das ações promovidas nos campos políticos, econômico e social, em suma, provoca o debate público. Porém, o que se verifica é uma assessoria de imprensa do governo que visa projetar uma imagem positiva da atual administração. As matérias da AEN investem mais na defesa dos interesses do governo do que na prestação de contas e o estímulo para o engajamento da população nas políticas adotadas. 
Comunicação pública não deve ser um instrumento de promoção política dos governos, mas sim uma forma de um governo prestar contas e levar ao conhecimento da opinião pública projetos, ações, atividades e políticas que realiza e que são de interesse público. Na matéria sobre as PPPs, foi destacado que o governo criou um link com perguntas e respostas sobre o tema, mas é somente para tirar dúvidas e não iniciar discussão.

Informações jornalísticas não somente informam, mas também formam opinião. E as informações da AEN induzem os leitores à simpatia ao governo em exercício. Isso se observa no uso das fontes, que geralmente são integrantes do próprio governo e fazem a defesa do ponto de vista da atual gestão.

Outro ponto que merece destaque é o silêncio por parte do governo. Enquanto um assunto polêmico envolvendo a administração estadual está em alta na imprensa, a AEN silencia. Nas três matérias analisadas, o tema foi publicado na agência apenas uma vez e para defesa do interesse do governo, contrariando a defesa de Bucci (2009) de que as empresas públicas de comunicação não devem direcionar a formação da opinião pública, mas informar. Ele levou esse conceito para a antiga Radiobrás, hoje Empresa Brasil de Comunicação (EBC). Segundo o autor, não é função da Radiobrás tutelar ou direcionar a formação da opinião pública, mas fornecer informações necessárias para que os cidadãos formem livremente a própria opinião.

Essa seria uma sugestão para a AEN se tornar independente e com maior credibilidade. No caso da Radiobrás, Bucci ressalta que o resultado foi obtido com a implementação de valores como: respeito ao caráter público da atividade, ao buscar a Excelência e ao exercer a transparência, interna e externa; respeito à cidadania, ao assumir o compromisso permanente com a universalização do direito à informação, por meio do canal direto com o público; respeito às diferenças, por meio do diálogo; respeito às pessoas, ao promover a felicidade no trabalho, a criatividade e a inovação. $\mathrm{O}$ autor ressalta que tendo o respeito como base, a ética se concretiza na renovação cotidiana de credibilidade da Radiobrás junto à sociedade brasileira e aos funcionários da empresa. 


\section{Referências}

ARBEX Jr., José. Showrnalismo - A Noticia Como Espetáculo. São Paulo, Casa Amarela, 2001.

BRANDÃO, Elizabeth Pazito. Conceito de comunicação pública. In DUARTE, Jorge. Comunicação pública. Estado, Mercado, Sociedade e Interesse Público. São Paulo, Atlas, 2009.

BUCCI, Eugênio. Caso Radiobrás: o compromisso com a verdade no jornalismo de uma empresa pública. In DUARTE, Jorge. Comunicação pública. Estado, Mercado, Sociedade e Interesse Público. São Paulo, Atlas, 2009.

FLOR, Gisele; BOMFIM, Filomena Maria Avelina. As Agências de Notícias como Fonte de Informação no Jornal Último Segundo. In RIBAS, Felipe de Freitas. Agência Estadual de Notícias: Estrutura e Rotina Produtiva. Monografia de conclusão do curso de jornalismo da Universidade Estadual de Ponta Grossa. Ponta Grossa, PR, 2010.

FOUCAULT, Michel. A ordem do discurso. Éditions Gallimard, Paris, 1971.

ORLANDI, Eni P. Análise de discurso - Princípios \& procedimentos. São Paulo, Pontes, 1999.

RIBAS, Felipe de Freitas. Agência Estadual de Notícias: Estrutura e Rotina Produtiva. Monografia de conclusão do curso de jornalismo da Universidade Estadual de Ponta Grossa. Ponta Grossa, PR, 2010. 


\section{Anexos}

Governo retira daAssembleia projeto da Agência Reguladora - 08/08/2011 19h50

Por decisão do governador Beto Richa, o governo estadual solicitou nesta segunda-feira (08/08) a retirada da pauta da Assembleia Legislativa e a devolução do projeto de lei que cria a Agência Reguladora de Serviços Públicos Delegados do Paraná (Agepar).

Segundo o deputado estadual Ademar Traiano, líder do governo no legislativo, a intenção é revisar e melhorar o texto para que não pairem dúvidas sobre as intenções da proposição.

"A agência vai regular atividades concedidas nas quais o Estado é minoritário ou não tem participação", afirma o parlamentar. "Serviços onde o Estado é majoritário não precisam de regulação e o governo quer fortalecer as empresas públicas.”

Após a revisão do texto, o projeto de lei será reencaminhado para votação na Assembleia.

\section{Emendas para saúde, segurança, educação e social terão prioridade, diz Richa - 11/10/2011 13h00}

O governador Beto Richa reuniu deputados estaduais no Palácio das Araucárias, na noite de segunda-feira (10), para discutir a proposta orçamentária do Estado para 2012 e apresentar projetos do governo que serão enviados para apreciação do Legislativo, entre eles a lei que institui as Parcerias Público-Privadas (PPPs). "O diálogo é a marca forte do governo e queremos manter abertos os canais com todos os representantes da população paranaense no legislativo”, disse Richa.

Mais de 40 parlamentares atenderam ao convite do governador. Eles foram informados de que as emendas dirigidas às áreas de saúde, segurança pública, educação e desenvolvimento social, que são prioridade no plano de governo, terão privilégio para liberação de recursos na execução do orçamento do ano que vem. 
Richa informou também que ainda em 2011 o Estado vai aplicar recursos orçamentários em obras e programas nas áreas consideradas prioritárias para o governo. Ele pediu aos deputados que indiquem onde os investimentos podem ser realizados a partir de emendas que ainda não foram liberadas. "Temos um foco de trabalho muito claro, que é oferecer serviços de qualidade à população. Saúde, segurança, educação e desenvolvimento social sempre terão nossa total atenção. Já fizemos isso em Curitiba e deu resultado", destacou o governador.

De acordo com o secretário-chefe da Casa Civil, Durval Amaral, as emendas permitem a participação efetiva dos deputados no orçamento do Estado. “A liberação desses recursos será condicionada à programação de ações do governo, para atender escolas, hospitais, asfalto nos municípios, por exemplo", afirmou.

O presidente da Assembleia Legislativa, deputado Valdir Rossoni, disse que a convocação dos parlamentares representa uma importante abertura do debate em torno do orçamento. "Mostra que o governo não tem dono, mas que governa para o povo e que convoca os parlamentares para legislar pelo povo. Esse debate facilita a tramitação e adianta a votação e aprovação do orçamento, que antes era feita apenas no último dia da legislatura”, disse Rossoni.

O líder do governo no legislativo, deputado Ademar Traiano, disse que a Assembleia tem sido respeitada e prova disso era presença de mais de 40 deputados no encontro com o governador. Traiano afirmou que o governo não irá discriminar nenhum deputado na liberação de recursos de emendas ao orçamento, independentemente de partido ou das críticas dirigidas ao governo. "O debate antecipado torna a tramitação mais tranqüila e rápida e é importante para o bom entendimento do Executivo com o Legislativo", disse ele.

PPP — No encontro, os deputados também conheceram as linhas básicas da proposta de projeto de lei que institui as Parcerias PúblicoPrivadas (PPPs) no Paraná. Os parlamentares assistiram a uma palestra com um especialista da consultoria internacional KPMG. A empresa é parceira do Movimento Brasil Competitivo (MBC), entidade com a qual 
o Governo do Paraná assinou um protocolo de intenções para implantar o programa Modernizando a Gestão Pública.

Para o consultor Charles Schramm, que apresentou o tema para secretários estaduais também nesta segunda-feira, o Paraná dá um passo rumo à modernidade ao acrescentar as PPPs como instrumento de políticas públicas aos mecanismos de que o Estado já dispõe. “É uma demonstração séria de quem deseja resolver os problemas da sociedade”, afirma.

A flexibilidade dos contratos privados para questões de tecnologia e outras soluções para cumprir cronogramas; a troca de conhecimento com o setor público e o aumento da capacidade de investimento do estado são algumas das vantagens do uso de PPPs, segundo o especialista. "Em vez de investir em um projeto único, o Estado pode optar por três ou quatro, ao mesmo tempo, e obter benefícios mais rapidamente”, explica Schramm.

FERRAMENTA DE GESTÃO - O secretário do Planejamento, Cássio Taniguchi, disse que PPPs são uma nova ferramenta de gestão à disposição do setor público para garantir e aumentar a oferta de serviços de qualidade à população, sem precisar custear diretamente os investimentos necessários. “A PPP representa um conceito mais amplo do que apenas fazer uma obra, como um hospital ou uma ferrovia, mas principalmente colocar o serviço à disposição da população, com eficiência, eficácia, pontualidade”, disse Taniguchi. “E ao fim do prazo, que geralmente é longo, aquele bem é devolvido ao setor público, o que torna um processo diferente de privatização”, enfatiza.

Para o secretário da Infraestrutura e Logística, José Richa Filho, os exemplos de PPPs em andamento em diversos segmentos em todo o Brasil mostram que esta é uma grande opção também para o Paraná. “É uma ferramenta espetacular. Não serve para tudo, mas bem empregada, poderá ajudar muito, por exemplo, na área de ferrovias e de rodovias estaduais, onde temos grandes demandas”, afirma o secretário. “Assim, o recurso público poder ser usado em outras áreas”.

Para facilitar a compreensão de o que são Parcerias Público Privadas e como elas funcionam, a Secretaria de Estado do Planejamento preparou 
um conjunto de perguntas e respostas que podem ser acessadas no site www.planejamento.pr.gov.br. A secretaria também está à disposição para responder outras dúvidas que podem ser enviadas no link “fale conosco”, da mesma página na internet.

\section{Gestores da área da saúde apóiam projeto de Organizações} Sociais - 05/12/2011 20h10

Gestores de instituições da área da saúde do Paraná defenderam nesta segunda-feira (5), em reunião com o governador Beto Richa, no Palácio das Araucárias, em Curitiba, o projeto de lei que autoriza o governo a repassar para Organizações Sociais (OS) a execução de serviços hoje sob a responsabilidade do Estado. A proposta - que exclui o repasse de atividades exclusivas do poder público, como ensino regular e segurança pública - deverá ser votado ainda esta semana pelos deputados estaduais.

José Álvaro Carneiro, diretor do Hospital Pequeno Príncipe, disse que a resistência de alguns segmentos às OS é calcada em notícias a respeito de organizações envolvidas em irregularidades. "Mas éimportante destacar que essas são minoria. A grande maioria das organizações presta excelentes serviços. No Paraná, as organizações sociais têm um papel muito relevante”, afirmou. Ele citou como exemplos a Santa Casa de Misericórdia e o próprio Hospital Pequeno Príncipe. “A Santa Casa é uma OS criada no final do século 19, e que vem prestando importantes serviços à comunidade há mais de cem anos. O Pequeno Príncipe está há 92 anos atendendo milhares de crianças, com uma gestão exemplar, auditada, transparente”, disse.

O superintendente do Hospital Erasto Gaertner, José Clemente Linhares, também defendeu o projeto. “A experiência do Erasto Gaertner e das outras instituições aqui representadas mostra que a parceria entre o governo do Estado e as OS é possível e necessária. A flexibilidade das Organizações Sociais - para contratação de serviços, por exemplo garante agilidade no atendimento, o que significa ampliar o acesso da população aos serviços de saúde”, disse. 
O governador destacou que o projeto visa superar amarras que hoje impedem a prestação de um bom serviço público em algumas áreas, como a da saúde. “O objetivo é repassar serviços em algumas áreas pontuais do governo, com rigoroso acompanhamento do Estado, metas e objetivos a serem cumpridos, prestação de contas e aprovação pelo Tribunal de Contas", afirmou.

Participaram da reunião representantes de entidade ligadas às áreas da saúde, cultura e educação; os deputados estaduais Marcelo Rangel, César Silvestri Filho e Douglas Fabrício, o deputado federal Rubens Bueno e os prefeitos de Curitiba, Luciano Ducci, de Piraquara, Gabriel Samaha, e de Tunas do Paraná, Jorge Tavares.

EMENDAS - Na mesma reunião, o deputado federal Rubens Bueno informou ao governador que apresentou emenda ao orçamento da União para 2012 destinando R\$ 2,33 milhões para compra de equipamentos e manutenção de serviços da saúde no Paraná, inclusive para Organizações Sociais (OSs). Também foram apresentadas as emendas orçamentárias 2012 da bancada federal e as emendas em execução. 